\title{
An analyzing case: Numbers of Taiwanese students and their expenditures by using grey system theory to forecast
}

\author{
Hoang Xuan Phuc Trinh ${ }^{1, *}$, Thanh-Tuyen Tran ${ }^{2}$ \\ ${ }^{1}$ Management Department, Binh Duong Economics and Technology University, Binh Duong, Vietnam \\ ${ }^{2}$ Scientific Research Office, Lac Hong University, No.10 Huynh Van Nghe, Bien Hoa, Dong Nai, Vietnam
}

\section{A R T I C L E I N F O}

\section{Article history:}

Received 3 June 2017

Received in revised form

27 July 2017

Accepted 27 July 2017

\section{Keywords:}

Taiwan education

Numbers of students

Discipline

Trending

Educational expenditure

Grey system theory

Forecasting

\begin{abstract}
A B S T R A C T
Taiwan is one of the Asian tigers with the education is directly linked to the quality of high-qualified human resources for supplying to the domestic labor market and the innovating industry. However, from the years 2010s, Taiwan higher education has been in emergency of dealing with the difficulty of demographic in the context of education increased desires in recent years. This study adapted data from Taiwanese Ministry of Education with the raising quantity of student from 1,326,029 (2007) to 1,346,221 (2014) together with the student's expenditure is approximately at $200,000 \mathrm{NTD} /$ year. Grey system theory is applied in this study with the three models GM $(1,1)$, DGM $(1,1)$ and Verhulst which are then chosen the most appropriate one. GM $(1,1)$ forecasts the increasing in student's expenditure about $36 \%$ to the future together with the downward in trends of student in the highest-percentage majors i.e. Social Sciences, Business and Law, Engineering, meanwhile, the impressive upward trends are in Humanities and Art, Service (from $10 \%$ to $15 \%$ up). In addition, the study also sees that the development scale of adult is becoming stable, the affordability of residents to adult higher education, the level of economic development and so forth. The research's result could be an advantage reference to education managers for dealing with the issues from quantity.
\end{abstract}

(C) 2017 The Authors. Published by IASE. This is an open access article under the CC BY-NC-ND license (http://creativecommons.org/licenses/by-nc-nd/4.0/).

\section{Introduction}

Taiwan is ranked highly in terms of freedom of the press, health care, human development, and economic freedom and especially in the field of public education (Yao et al., 2009). One reason for Taiwan's economic development is its quality human resources, an accomplishment closely tied to the issue of education. Education in Taiwan provides highly-qualified staffs in sufficient supply to the domestic labor market, and brings positive benefits for industry innovation (Lin, 2004; Bourguignon et al., 2005). However, Taiwan education is now also greatly affected by the elements of globalization, decreasing fertility, the digital age and an aging society (MOE, 2013). To overcome these difficulties, the government needs to respond to social situation immediately by creating a blueprint for cultivating excellence for the next 10 years, based on the retention and recruitment of highly skilled people,

\footnotetext{
* Corresponding Author.

Email Address: thxphuc@ktkt.edu.vn (H.X. P. Trinh) https://doi.org/10.21833/ijaas.2017.09.005

2313-626X/C) 2017 The Authors. Published by IASE.

This is an open access article under the CC BY-NC-ND license

(http://creativecommons.org/licenses/by-nc-nd/4.0/)
}

with the goal of developing human resources' ability to compete in the international community and to establish a firm footing for the nation.

In order to meet the needs of society, the Taiwanese Ministry of Education led an expansion of higher education system both in term of number of colleges and universities from 28 in 1986 to 149 in 2007 and the size of the student population from 184,729 to 966,591 during the same period. In fact, all students can pursue higher education if they have the desire and ability; higher education in Taiwan has become the norm, not the exception. The paper of Huang et al. (2006) impressed that the rapid development and availability of higher education in Taiwan has increased college enrolment to more than $80 \%$ of those willing to partake. As the result, recently the government has been reducing its financial support for higher education institutions, while at the same time encouraging national universities to diversify their income resources $(\mathrm{Wu}$, 2009). Then, the tuition fees for national universities have rapidly expanded by more than 93\%, nearly doubling over the past decade. Students and their parents have to bear a greater part of the costs of higher education, which may lead to greater financial pressure on low-income undergraduates and which 
may ultimately affect their professional choices and opportunities in the future.

The purpose of this research is to provide the predicted numbers of students classify by selected majors in their higher education in the future, universities can provide suitable strategy for their policy. These empirical results can be also taken into consideration by Taiwanese government when formulating education policies and strategies. Moreover, students and parents will also get the first idea of how much the educational expenditure will be in the near future. The financial issue may affect these students' plans during their studying progress and even after their graduation. Students under economic pressure may quit or postpone their higher educational plans, because they need to make money immediately after college graduation in order to repay their debts, save money for future graduate school expenses, and look for a reason to justify returning to student status.

We use the data (with the frame time 1981-2012 for educational expenditure per student; 1998-2014 for number of students receiving university education) obtained from the website of Ministry of Education, R.O.C (Taiwan), and then we will apply Grey System theory for analyzing these data, which was formulated by Deng (1989) to study the problems of less data, poor information and uncertainty (Deng, 1986; Lin and Liu, 2004). In order to make positive analysis about the changes in numbers of students and the fluctuated of tuition fees in Taiwan educational system from 1980s to 2014 , and to make a prediction of these problems for the next04 coming years from 2015 and 2018, Grey system theory with its GM $(1,1), \operatorname{DGM}(1,1)$ and Verhulst are applied.

There will be some suggestions provided in the last chapters to the Ministry to deal with the changing in forecasted numbers. Furthermore, future works would continue to apply this method, and then if it's still successful, there would be very good for any nation's educational system. One of the main reasons for this objective is that there are a few prediction methods applied to the numbers in education, so this would contribute a lot of things to the whole country education development in longterm.

\section{Methodology}

\subsection{Fundamental concepts of grey system theory}

To see and have an overview about the future values through the past and current data is what it means by prediction (Liu et al., 2004). Grey prediction is to forecast the system using both clear data and changeable information. It means that Grey is used to make forecasting the time-related grey process of change in particular field or range (Cheng, 2003). It is also known as GM as to predict quantity on Grey Prediction Model. Step 1 is to input the data sequence of strong regularity by methods of grey generating to make less randomness of the original data flow. The second step it gets various equation model established to discover and gain the rule of sequence, also forecast the trend for the future of the current system (Nguyen and Tran, 2017a). Thus, a great leap can be easily achieved to set up the familiar and dynamic differential equation through fixed data source (Liu et al., 2004). In short, GM (1,1) is the most widely used and chosen to forecast the magnitude of numerical data leaned on the single time series data (Tang and Feng, 2007).

\section{GM (1, 1) Model}

In the literature, $\operatorname{GM}(1,1)$ type of grey model is highly used to do calculation - pronounced as "Grey Model First Order One Variable". This is a time series forecasting model, which is refreshed as the latest data coming available to the prediction model, and the differential equations of the $\operatorname{GM}(1,1)$ model have time-varying coefficients (Nguyen and Tran, 2017b; Nguyen and Tran, 2016).

The GM $(1,1)$ model can only be used in positive data sequences (Deng, 1989). This paper uses grey models to make prediction for the future values of the primitive data points since all the primitive data points are positive.

In order to smooth the randomness, the primitive data obtained from the system to form the $\operatorname{GM}(1,1)$ is subjected to an operator, named Accumulating Generation Operator (AGO) (Deng, 1989).

To obtain the n-step ahead predicted value of the system, this research solves the differential equation, GM $(1,1)$. Lastly, the Inverse Accumulating Generation Operator (IAG0) is applied to search for the predicted values of original data by the predicted value (Eq. 1).

$X^{(0)}=\left(x^{(0)}(1), x^{(0)}(2), \ldots, x^{(0)}(n)\right), \quad n \geq 4$,

where $X^{(0)}$ is a non-negative sequence and $\mathbf{n}$ is the sample size of the data. When this sequence is subjected to the Accumulating Generation Operation (AGO), the following sequence $X^{(1)}$ is obtained. It is obvious that $X^{(1)}$ is monotonically increasing (Eqs. 2 and 3).

$$
\begin{aligned}
& X^{(1)}=\left(x^{(1)}(1), x^{(1)}(2), \ldots, x^{(1)}(n)\right), \quad n \geq 4 \\
& x^{(1)}(k)=\sum_{i=1}^{k} x^{(0)}(i), \quad k=1,2,3 \ldots, n .
\end{aligned}
$$

The generated mean sequence of $Z^{(1)}$ of $X^{(1)}$ is defined as (Eq. 4):

$Z^{(1)}=\left(z^{(1)}(1), z^{(1)}(2), \ldots, z^{(1)}(n)\right)$,

where $z^{(1)}(k)$ is the mean value of adjacent data, i.e., (Eq. 5)

$z^{(1)}(k)=0.5 x^{(1)}(k)+0.5 x^{(1)}(k-1), \quad k=2,3, \ldots, n$.

The least square estimate sequence of the grey difference equation of GM $(1,1)$ is defined as follows (Deng, 1989) (Eq. 6): 
$x^{(0)}(k)+a z^{(1)}(k)=b$

The whitening equation is therefore, as follows (Eq. 7):

$\frac{d x^{1}(t)}{d t}+a x^{1}(t)=b$

In above, $[a, b]^{T}$ is a sequence of parameters that can be seen as follows (Eqs. 8-11):

$[a, b]^{T}=\left(B^{T} B\right)^{-1} B^{T} Y$,

$Y=\left[x^{(0)}(2), x^{(0)}(3), \ldots, x^{(0)}(n)\right]^{T}$,

$B=\left[\begin{array}{cc}-Z^{(1)}(2) & 1 \\ -Z^{(1)}(3) & 1 \\ \cdot & \cdot \\ \cdot & \cdot \\ -Z^{(1)}(n) & \cdot\end{array}\right]$

To the Eq. 7, the solution of $x^{(1)}(t)$ at time $\mathrm{k}$ :

$x_{p}^{(1)}(k+1)=\left[x^{(0)}(1)-\frac{b}{a}\right] e^{-a k}+\frac{b}{a}$.

The IAGO is calculated to show out the following grey model to obtain the predicted value of the primitive data at time $(\mathrm{k}+1)$ (Eq. 12).

$x_{p}^{(0)}(k+1)=\left[x^{(0)}(1)-\frac{b}{a}\right] e^{-a k}\left(1-e^{a}\right)$

and the predicted value of the primitive data at time $(\mathrm{k}+\mathrm{H})($ Eq. 13):

$x_{p}^{(0)}(k+H)=\left[x^{(0)}(1)-\frac{b}{a}\right] e^{-a(k+H-1)}\left(1-e^{a}\right)$.

\section{The grey Verhulst model}

A German biologist Pierre Franois Verhulst first introduced the Verhulst model with the main purpose to limit the whole development for a real system and to describe some increasing processes, such as an S-curve which has a saturation region (Nguyen and Tran, 2017b).

It defines the Grey Verhulst model as following (Wen and Huang, 2004) (Eq. 14):

$\frac{d x^{1}}{d x}+a x^{(1)}=b\left(x^{(1)}\right)^{2}$.

Or Grey difference equation of Eq. 14 is (Eqs. 15 and 16)

$x^{(0)}(k)+a z^{(1)}(k)=b\left(z^{(1)}(k)\right)^{2}$,

$x^{(0)}(k)=-a z^{(1)}(k)+b\left(z^{(1)}(k)\right)^{2}$. 17)

This formula is same to the GM $(1,1)$ model (Eq.

$[a, b]^{T}=\left(B^{T} B\right)^{-1} B^{T} Y$,

In which (Eqs. 18 and 19)

$Y=\left[x^{(0)}(2), x^{(0)}(3), \ldots, x^{(0)}(n)\right]^{T}$,
$B=\left[\begin{array}{cc}\left.-z^{(1)}(2) z^{(1)}(2)\right)^{2} \\ \left.-z^{(1)}(3) z^{(1)}(3)\right)^{2} \\ \cdot & \cdot \\ \cdot & \cdot \\ \left.-z^{(1)}(n) z^{(1)}(n)\right)^{2}\end{array}\right]$

$x^{(1)}(t)$ at time $\mathrm{k}$ is as follows (Eq. 20):

$x_{p}^{(1)}(k+1)=\frac{a x^{(0)}(1)}{b x^{(0)}(1)+\left(a-b x^{(0)}(1)\right) e^{a k}}$.

and applying the IAGO (Eq. 21):

$$
\begin{aligned}
X_{p}^{(0)}(k)= & \frac{a x^{(0)}(1)\left(a-b x^{(0)}(1)\right)}{\left(b x^{(0)}(1)+\left(a-b x^{(0)}(1)\right) e^{a(k-1)}\right.} \\
& * \frac{\left(1-e^{a}\right) e^{a(k-2)}}{\left(b x^{(0)}(1)+\left(a-b x^{(0)}(1)\right) e^{a(k-2)}\right.}
\end{aligned}
$$

As can be seen, in Eq. 21, if a $<0$, then

$$
\lim _{k \rightarrow \infty} x_{p}^{(1)}(k+1) \rightarrow \frac{a}{b}
$$

It means that the saturation point in Eq. 20 is $\frac{a}{b}$, which limits the prediction value. It is also the saturation point of $X_{p}^{(0)}(k)$ (Wen and Huang, 2004).

As long as $\mathbf{k}$ is large enough, then $x_{p}^{(1)}(k+1)$ and $x_{p}^{(1)}(k)$ would be very close. Due to this particular feature of this model, it is commonly applied to make description and prediction processes with a saturation area (Wang et al., 2015; Nguyen and Tran 2015; Nguyen et al., 2015).

\section{$\operatorname{DGM}(1,1)$}

Discrete Grey Model (DGM) is adopted to do the task of forecasting employment by industry, which is shown step-by-step as below.

$\mathrm{x}^{(1)}(\mathrm{k}+1)=\beta_{1} \mathrm{x}^{(1)} \beta_{2}$ is written as a basic of discrete grey model (DGM) or a discretization of the GM $(1,1)$ model (Kayacan et al., 2010).

Theorem 1: $\operatorname{Let} \mathrm{X}^{(0)}=\left\{\mathrm{x}^{(0)}(1), \mathrm{x}^{(0)}(2), \ldots, \mathrm{x}^{(0)} \mathrm{n}\right\}$ be a nonnegative sequence and its accumulation generation $X^{(1)}=\left\{x^{(1)}(1), x^{(1)}(2), \ldots, x^{(1)} n\right\}$. If $\hat{\beta}=$ $\left(\beta_{1}, \beta_{2}\right)^{\mathrm{T}}$ is the parametric sequence and (Eq. 22)

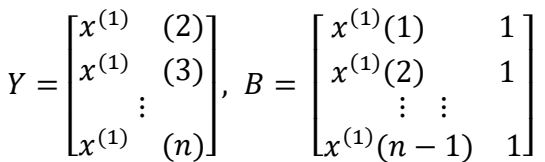

Then the least squares estimates of the parameters of the discrete model (Eq. 23)

$x^{(1)}(k+1)=\beta_{1} x^{(1)}(k)+\beta_{2}$ satisfy $\hat{\beta}=\left(B^{T} B\right)^{-1} B^{T} Y$.

Proof: Substituting the data sequence into the grey differential equation (Eq. 24)

$x^{(1)}(k+1)=\beta_{1} x^{(1)}(k)+\beta_{2}$

produces 
$x^{(1)}(2)=\beta_{1} x^{(1)}(1)+\beta_{2}$

$x^{(1)}(3)=\beta_{1} x^{(1)}(2)+\beta_{2}$

$x^{(1)}(n)=\beta_{1} x^{(1)}(n-1)+\beta_{2}$

This is $B \hat{\beta}=Y$. For a pair of estimated values of $\beta_{1}, \beta_{2}$, using $\beta_{1} x^{(1)}(k)+\beta_{2}$ to substitute $x^{(1)}(k+1), k=1,2, \ldots, n-1$, on the left-hand side leads to the error sequence $\varepsilon=Y-B \hat{\beta}$. Assume that (Eq. 25)

$S=\varepsilon^{T} \varepsilon=(Y-B \hat{\beta})^{T}(Y-B \hat{\beta})=\sum_{k=1}^{n-1}\left(x^{(1)}(k+1)-\right.$ $\left.\beta_{1} x^{(1)}(k)-\beta_{2}\right)^{2}$.
So, the values of $\beta_{1}, \beta_{2}$ making $S$ the smallest possible satisfy (Eq. 26)

$\left\{\begin{array}{l}\frac{\partial S}{\partial \beta_{1}}=-2 \sum_{k=1}^{n-1}\left(x^{(1)}(k+1)-\beta_{1} x^{(1)}(k)-\beta_{2}\right) \cdot x^{(1)}(k)=0 \\ \frac{\partial S}{\partial \beta_{1}}=-2 \sum_{k=1}^{n-1}\left(x^{(1)}(k+1)-\beta_{1} x^{(1)}(k)-\beta_{2}\right)=0\end{array}\right.$

Solving this system of equations produces

$$
\left\{\begin{array}{c}
\beta_{1}=\frac{\sum_{k=1}^{n-1}\left(x^{(1)}(k+1)(k)\right)-\frac{1}{n-1} \sum_{k=1}^{n-1}\left(x^{(1)}(k+1)\right) \sum_{k=1}^{n-1}\left(x^{(1)}(k)\right)}{\sum_{k=1}^{n-1}\left(x^{(1)}(k)\right)^{2}-\frac{1}{n-1} \sum_{k=1}^{n-1}\left(x^{(1)}(k)\right)^{2}} \\
\beta_{2}=\frac{1}{n-1}\left[\sum_{k=1}^{n-1}\left(x^{(1)}(k+1)\right)-\beta_{1} \sum_{k=1}^{n-1}\left(x^{(1)}(k)\right)\right]
\end{array}\right.
$$

From $B \hat{\beta}=Y$, it follows that (Eq. 27)

$B^{T} B \hat{\beta}=B^{T} Y, \hat{\beta}=\left(B^{T} B\right)^{-1} B^{T} Y$

However, from (Eq. 28)

$B^{T} B=\left[\begin{array}{ccc}x^{(1)}(1) & 1 \\ x^{(1)}(2) & 1 \\ \vdots & \vdots & 1 \\ x^{(1)}(n-1) & 1\end{array}\right]^{T}\left[\begin{array}{ccc}x^{(1)}(1) & 1 \\ x^{(1)}(2) & 1 \\ \vdots & \vdots & \\ x^{(1)}(n-1) & 1\end{array}\right]=$
$\left[\begin{array}{cc}\sum_{k=1}^{n-1}\left(x^{(1)}(k)\right)^{2} & \sum_{k=1}^{n-1}\left(x^{(1)}(k)\right) \\ \sum_{k=1}^{n-1}\left(x^{(1)}(k)\right) & n-1\end{array}\right]$

$\hat{\beta}=\left(B^{T} B\right)^{-1} B^{T} Y=\frac{1}{(n-1) \sum_{k=1}^{n-1}\left(x^{(1)}(k)\right)^{2}-\left[\sum_{k=1}^{n-1}\left(x^{(1)}(k)\right)\right]^{2}} \times$

$\left[\begin{array}{c}(n-1) \sum_{k=1}^{n-1} x^{(1)}(k) x^{(1)}(k+1)-\sum_{k=1}^{n-1}\left(x^{(1)}(k)\right) \sum_{k=1}^{n-1} x^{(1)}(k+1) \\ -\sum_{k=1}^{n-1}\left(x^{(1)}(k)\right) \sum_{k=1}^{n-1} x^{(1)}(k) x^{(1)}(k+1)+\sum_{k=1}^{n-1} x^{(1)}(k+1) \sum_{k=1}^{n-1}\left(x^{(1)}(k)\right)^{2}\end{array}\right]=$

$\left[\begin{array}{c}\frac{\sum_{k=1}^{n-1} x^{(1)}(k) x^{(1)}(k+1)-\frac{1}{n-1} \sum_{k=1}^{n-1} x^{(1)}(k+1) \sum_{k=1}^{n-1}\left(x^{(1)}(k)\right)}{\sum_{k=1}^{n-1}\left(x^{(1)}(k)\right)^{2}-\frac{1}{n-1} \sum_{k=1}^{n-1}\left(x^{(1)}(k)\right)^{2}} \\ \frac{1}{n-1} \sum_{k=1}^{n-1} x^{(1)}(k+1)-\beta_{1} \sum_{k=1}^{n-1} x^{(1)}(k)\end{array}\right]=\left[\begin{array}{l}\beta_{1} \\ \beta_{2}\end{array}\right] . \quad Q E D$.

Theorem 2: Let $B, Y, \hat{\beta}$ be the same as defined in Theorem 1 , and $\hat{\beta}=\left[\begin{array}{l}\beta_{1} \\ \beta_{2}\end{array}\right]=\left(B^{T} B\right)^{-1} B^{T} Y$. Then the following hold true (Eqs. 30 and 31 ):

(1) If $x^{(1)}(1)=x^{(0)}(1)$, the recurrence relation is

$\hat{x}^{(1)}(k+1)=\beta_{1}^{k} x^{(0)}(1)+\frac{1-\beta_{1}^{k}}{1-\beta_{1}} * \beta_{2} ; k=1,2, \ldots n-1 ;$

Or

$\hat{x}^{(1)}(k+1)=\beta_{1}^{k}\left(x^{(0)}(1)-\frac{\beta_{2}}{1-\beta_{1}}\right)+\frac{\beta_{2}}{1-\beta_{1}} ; k=1,2, \ldots n-1$

(2) The restored values are

$$
\begin{aligned}
& \left(B^{T} B\right)^{-1}=\frac{1}{(n-1) \sum_{k=1}^{n-1}\left(x^{(1)}(k)\right)^{2}-\left[\sum_{k=1}^{n-1}\left(x^{(1)}(k)\right)\right]^{2}} \times \\
& {\left[\begin{array}{cc}
n-1 & -\sum_{k=1}^{n-1}\left(x^{(1)}(k)\right) \\
-\sum_{k=1}^{n-1}\left(x^{(1)}(k)\right) & \sum_{k=1}^{n-1}\left(x^{(1)}(k)\right)^{2}
\end{array}\right]}
\end{aligned}
$$$$
B^{T} Y=\left[\begin{array}{ccc}
x^{(1)}(1) & 1 \\
x^{(1)}(2) & 1 \\
\vdots & \vdots & \\
x^{(1)}(n-1) & 1
\end{array}\right]^{T}\left[\begin{array}{c}
x^{(1)}(2) \\
x^{(1)}(3) \\
\vdots \\
x^{(1)}(n)
\end{array}\right]=
$$$$
\left[\begin{array}{c}
\sum_{k=1}^{n-1} x^{(1)}(k) \cdot x^{(1)}(k+1) \\
\sum_{k=1}^{n-1} x^{(1)}(k+1)
\end{array}\right]
$$

It follows that (Eq. 29) $\hat{x}^{(0)}(k+1)=\alpha^{(1)} \hat{x}^{(1)}(k+1)=\hat{x}^{(1)}(k+1)-\hat{x}^{(1)}(k) ; k=$ $1,2, \ldots, n-1$

Proof: (1) Substituting the obtained $\beta_{1}, \beta_{2}$ into the discrete form produces
$\hat{x}^{(0)}(k+1)=\beta_{1} \hat{x}^{(1)}(k)+\beta_{2}=\beta_{1}\left(\beta_{1} \hat{x}^{(1)}(k-1)+\right.$ $\left.\beta_{2}\right)+\beta_{2}=\cdots=\beta_{1}^{k} x^{(1)}(1)+\left(\beta_{1}^{k-1}+\beta_{1}^{k-2}+\cdots+\beta_{1}+\right.$ 1). $\beta_{2}$

Letting $x^{(1)}(1)=x^{(0)}(1)$ leads to

$\hat{x}^{(1)}(k+1)=\beta_{1}^{k} x^{(0)}(1)+\frac{1-\beta_{1}^{k}}{1-\beta_{1}} \cdot \beta_{2}$

So then (2) 
$\hat{x}^{(1)}(k+1)-\hat{x}^{(1)}(k)=\sum_{i=1}^{k+1} \hat{x}^{(0)}(i)-\sum_{i=1}^{k} \hat{x}^{(0)}(i)=$ $\hat{x}^{(0)}(k+1) \cdot Q E D$.

For full reference, see (Kayacan et al., 2010) chapter 5.

\subsection{Calculating process of grey system theory}

The basic mathematical model of Grey system GM $(1,1)$, Verhulst and DGM $(1,1)$ is the foundation to make progress for the program of grey forecasting.
Following is the Flow chart of Grey System Theory based on MATLAB (Zhang and Li, 2010).

\subsection{Calculation and applying $\mathrm{GM}(1,1)$}

This paper is about to apply the grey prediction model GM $(1,1)$ as the study focus. It precedes the prediction based on historical data of the number of students receiving higher education by discipline and educational expenditure per student at all levels announced by the Taiwanese Ministry of Education and Training from 1998 to 2014.

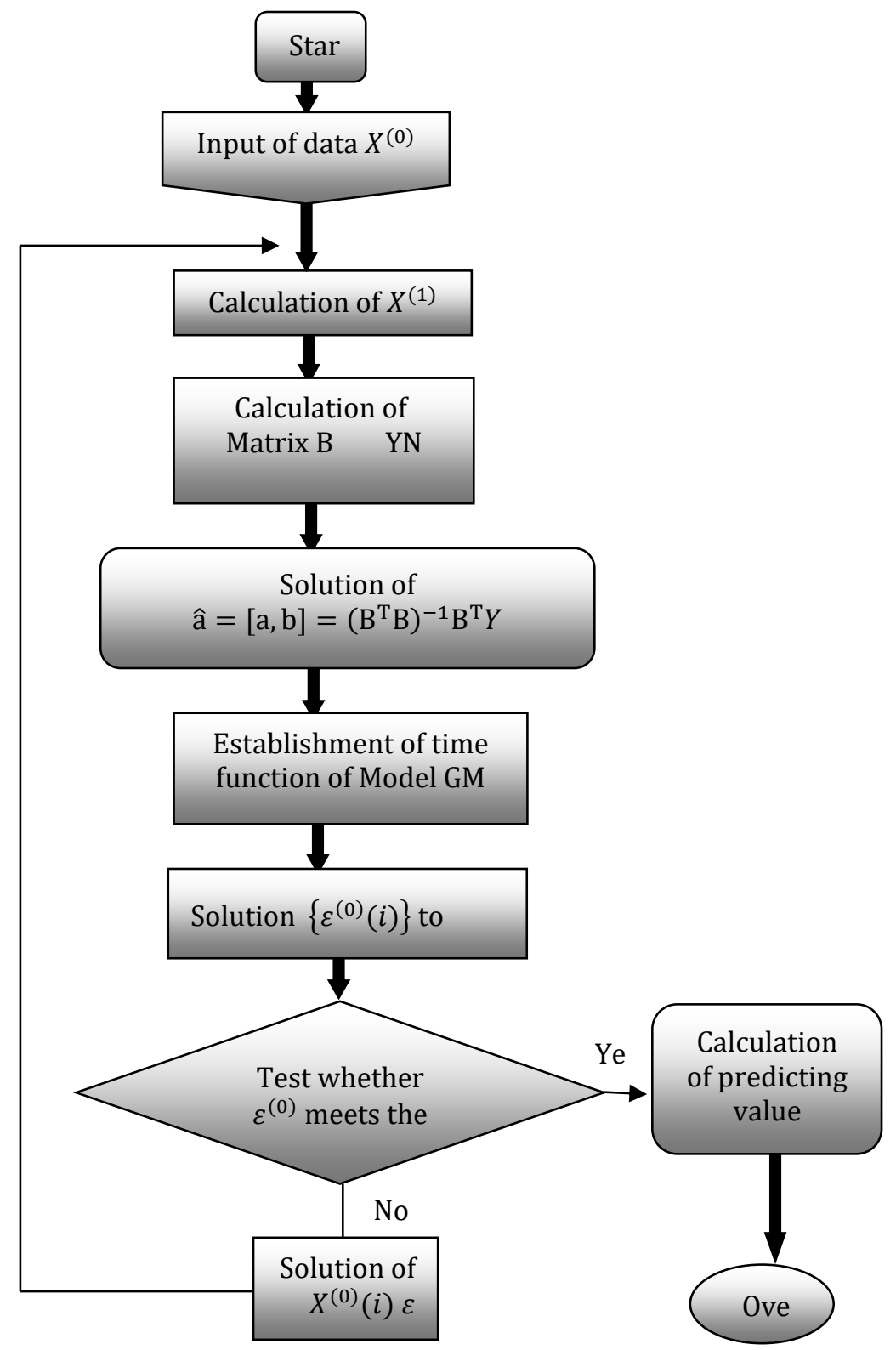

Fig. 1: The flow chart of grey system theory based on MATLAB

Firstly, take the total number of student data from the academic years 2007 to 2014 as example to understand how to compute in GM $(1,1)$ model, and then in accordance with the grey prediction method, do the calculation in the following steps:

The original series are:

$$
\begin{aligned}
& x^{(0)} \\
& =\left(x^{(0)}(1), x^{(0)}(2), x^{(0)}(3), x^{(0)}(4), x^{(0)}(5), x^{(0)}(6), x^{(0)}(7)\right) \\
& =(1326029,1337455,1336659,1343723,1352225, \\
& 1355490,1346221)
\end{aligned}
$$

and then use the least square method to find $a$ and $b$

$$
\left[\begin{array}{l}
a \\
b
\end{array}\right]=\theta=\left(B^{T} B\right)^{-1} B^{T} y_{N}=\left[\begin{array}{c}
-0.0023074 \\
1332944.063
\end{array}\right]
$$


use the two coefficients $a$ and $b$ to generate the whitening equation of the differential equation:

$\frac{d x^{(1)}}{d t}(-0.0023074) \times x^{(1)}=1332944.063$

find the prediction model from Equation:

$X^{(1)}(k+1)=\left(X^{(0)}(1)-\frac{b}{a}\right) e^{-a k}+\frac{b}{a}$

$$
\begin{aligned}
& x^{(1)}(k+1)=\left(1326029-\frac{1332944.63}{-0.0023074}\right) e^{0.0023074 k} \\
& +\frac{1332944.063}{-0.0023074}
\end{aligned}
$$

substitute different values of $\mathrm{k}$ into the equation (Table 1):

$k=0 \rightarrow X^{(1)}(1)=1326029$

Derive the predicted value of the original series according to the accumulated generating operation and obtain:

Table 1: The predicted value of the original series

\begin{tabular}{ccccc}
\hline Year & k value & Actual value & Forecasted value & Residual error (F-A) \\
\hline $2007-08$ & 1 & $1,326,029$ & $1,326,029$ & 0 \\
$2008-09$ & 2 & $1,337,455$ & $1,337,546$ & 91 \\
$2009-10$ & 3 & $1,336,659$ & $1,340,636$ & 3977 \\
$2010-11$ & 4 & $1,343,723$ & $1,343,733$ & 10 \\
$2011-12$ & 6 & $1,352,225$ & $1,346,837$ & -5388 \\
$2012-13$ & 7 & $1,355,490$ & $1,349,949$ & -5541 \\
$2013-14$ & 8 & $1,346,221$ & $1,353,067$ & 6846 \\
$2014-15$ & 9 & -- & $1,356,193$ & -- \\
$2015-16$ & 10 & -- & $1,359,326$ & -- \\
$2016-17$ & 11 & -- & $1,362,466$ & -- \\
$2017-18$ & 12 & -- & $1,365,614$ & -- \\
\hline
\end{tabular}

After next, this paper uses the Matlab with the forecasting method on Grey system model.

\subsection{Calculation and applying Verhulst}

The Verhulst model was first introduced by a German biologist Pierre Franois Verhulst. The main purpose of Verhulst model is to limit the whole development for a real system and it is effective in describing some increasing processes, such as an Scurve which has a saturation region (Eq. 35).

$\mathrm{x}^{(0)}(\mathrm{k})+\mathrm{az}{ }^{(1)}(\mathrm{k})=\mathrm{b}\left(\mathrm{z}^{(1)}(\mathrm{k})\right)^{\alpha}$

is established as the GM $(1,1)$ power model, and (Eq. 36)

$\frac{d x^{(1)}}{d t}+a x^{(1)}=b\left(x^{(1)}\right)^{\alpha}$

is known as the whitenization equation of $\operatorname{GM}(1,1)$ power model when: $X^{(0)}$ is assumed to be a sequence of raw data; $X^{(1)}$ : a sequence of accumulation of generation of $\mathrm{X}^{(0)} ; \mathrm{Z}^{(1)}$ : adjacent neighbor mean of $\mathrm{X}^{(1)}$ (Eq. 37).

\section{Theorem 1: Then}

$x^{(1)}(t)=\left\{e^{-(1-a) a t}\left[(1-a) \int b e^{(1-a) a t} d t+c\right]\right\}^{\frac{1}{1-a}}$

is the solution of Eq. 36.

Theorem 2: With $\mathrm{X}^{(0)} ; \mathrm{X}^{(1)}$ and $\mathrm{Z}^{(1)}$ (as above), let

$$
\mathrm{B}=\left[\begin{array}{cc}
-\mathrm{z}^{(1)}(2) & \left(\mathrm{z}^{(1)}(2)\right)^{\alpha} \\
-\mathrm{z}^{(1)}(3) & \left(\mathrm{z}^{(1)}(3)\right)^{\alpha} \\
\vdots & \vdots \\
-\mathrm{z}^{(1)}(\mathrm{n}) & \left(\mathrm{z}^{(1)}(\mathrm{n})\right)^{\alpha}
\end{array}\right], \mathrm{Y}=\left[\begin{array}{c}
\mathrm{x}^{(0)}(2) \\
\mathrm{x}^{(0)}(3) \\
\vdots \\
\mathrm{x}^{(0)}(\mathrm{n})
\end{array}\right]
$$

then the least squares estimate of the parametric sequence $\hat{a}=[a, b]^{\mathrm{T}}$ of the Eq. 35 isâ $=\left(\mathrm{B}^{\mathrm{T}} \mathrm{B}\right)^{-1} \mathrm{~B}^{\mathrm{T}} \mathrm{Y}$.

When the power of the Eq. $35 \alpha=2$, the resultant model is (Eq. 38)

$\mathrm{x}^{(0)}(\mathrm{k})+\mathrm{az}(1)(\mathrm{k})=\mathrm{b}\left(\mathrm{z}^{(1)}(\mathrm{k})\right)^{2}$

This is the grey Verhulst model, and (Eq. 39)

$\frac{d x^{(1)}}{d t}+a x^{(1)}=b\left(x^{(1)}\right)^{2}$

This is known as the whitenization equation of grey Verhulst.

Theorem 3: The solution of Eq. 38 is (Eq. 40)

$$
\begin{aligned}
& \mathrm{x}^{(1)}(\mathrm{t})=\frac{1}{\mathrm{e}^{\mathrm{at}}\left[\frac{1}{\mathrm{x}^{(1)}(0)}-\frac{\mathrm{b}}{\mathrm{a}}\left(1-\mathrm{e}^{-\mathrm{at}}\right)\right]}=\frac{\mathrm{ax}^{(1)}(0)}{\mathrm{e}^{\mathrm{at}}\left[\mathrm{a}-\mathrm{bx}^{(1)}(0)\left(1-\mathrm{e}^{-\mathrm{at}}\right)\right]} \\
& \frac{\mathrm{ax}(0)}{\mathrm{bx}^{(1)}(0)+\left(\mathrm{a}-\mathrm{bx}^{(1)}(0)\right) \mathrm{e}^{\mathrm{at}}}
\end{aligned}
$$

The time response sequence of the grey Verhulst model is (Eq. 41):

$\hat{\mathrm{x}}(\mathrm{k}+1)=\frac{\mathrm{ax}^{(1)}(0)}{\mathrm{bx}^{(1)}(0)+\left(\mathrm{a}-\mathrm{bx}^{(1)}(0)\right) \mathrm{e}^{\mathrm{ak}}}$

Next, Verhulst model's parameters are shown in Table 2 with $a, b$ values and other digit elements from Eq. 41, which is

$\widehat{\mathrm{x}}(\mathrm{k}+1)=\frac{\mathrm{ax}^{(1)}(0)}{\mathrm{bx}^{(1)}(0)+\left(\mathrm{a}-\mathrm{bx}^{(1)}(0)\right) \mathrm{e}^{\mathrm{ak}}}$.

Next, Verhulst model's parameters are shown in Table 3 with $a, b$ values and other digit elements from Eq. 20, which is

$\hat{\mathrm{x}}(\mathrm{k}+1)=\frac{\mathrm{ax}^{(1)}(0)}{\mathrm{bx}^{(1)}(0)+\left(\mathrm{a}-\mathrm{bx}^{(1)}(0)\right) \mathrm{e}^{\mathrm{ak}}}$. 
Table 2: The parameters of building Verhulst in forecasting process of researched factors

\begin{tabular}{|c|c|c|c|c|c|}
\hline & \multirow[t]{2}{*}{ a } & \multirow[t]{2}{*}{$\mathrm{b}$} & \multicolumn{2}{|c|}{$\hat{\mathrm{x}}(\mathrm{k}+1)=\frac{\mathrm{ax}^{(1)}(0)}{\mathrm{bx}^{(1)}(0)+\left(\mathrm{a}-\mathrm{bx}^{(1)}(0)\right) \mathrm{e}^{\mathrm{ak}}}(\mathrm{Eq} .20)$} & \multirow{2}{*}{$\begin{array}{l}\text { in which: } \\
\text { bx }^{(1)}(0)\end{array}$} \\
\hline & & & $\mathrm{ax}^{(1)}(0)$ & $a-b x^{(1)}(0)$ & \\
\hline Total Students & -0.4113 & -0.000000304 & -0.0079 & -0.0078 & -0.4035 \\
\hline
\end{tabular}

\subsection{Calculation and applying DGM $(1,1)$}

$x^{(1)}(k+1)=\beta_{1} x^{(1)} \beta_{2}$ is written as a basic of discrete grey model (DGM) or a discretization of the GM $(1,1)$ model. The overall procedure to obtain all details about Discrete Grey models can be referred to a full book about Grey Systems Theory written by Lin and Liu (2010), which is mentioned in chapter 2.

Table 3: The forecasting results for total Taiwanese students by Verhulst

\begin{tabular}{ccccc}
\hline Year & $\mathrm{k}$ value & Actual value & Forecasted value & Residual error (F-A) \\
\hline $2007-08$ & 1 & $1,326,029$ & $1,326,029$ & 0 \\
$2008-09$ & 2 & $1,337,455$ & $1,334,639$ & -2816 \\
$2009-10$ & 3 & $1,336,659$ & $1,340,408$ & 3749 \\
$2010-11$ & 4 & $1,343,723$ & $1,344,258$ & 535 \\
$2011-12$ & 6 & $1,352,225$ & $1,346,823$ & -5402 \\
$2012-13$ & 7 & $1,355,490$ & $1,348,528$ & -6962 \\
$2013-14$ & 8 & $1,346,221$ & $1,349,660$ & 3439 \\
$2014-15$ & 9 & $?$ & $1,350,910$ & -- \\
$2015-16$ & 10 & $?$ & $1,351,241$ & -- \\
$2016-17$ & 11 & $?$ & $1,351,460$ & - \\
$2017-18$ & 12 & $?$ & $1,351,606$ & - \\
\hline
\end{tabular}

Finally, the calculations with the parameters of $\operatorname{DGM}(1,1)$ are illustrated below: Total Revenue calculation is with the following parameters:

$\beta_{1}=1.0023 ; \beta_{2}=1334492.7544$,

so the equation:

$x^{(0)}(1)\left(\beta_{1}-1\right)+\beta_{2}=1337553.4691$.

With the above developed parameters, we also calculated to have the precious forecasting results which are illustrated in tables and figures concisely.
Table 4 shows the true values and forecasting results by $\operatorname{DGM}(1,1)$ model for total Taiwanese students for the next four years (2015-2018).

\subsection{Accuracy test and optimization of the model}

Numerous methods exist for judging forecasting model accuracy, and no single recognized inspection method exists for forecasting ability. Mean Absolute Percentage Error (MAPE) is often used to measure forecasting accuracy (Huang and Jane, 2009).

Table 4: The forecasting results for total Taiwanese students by DGM $(1,1)$

\begin{tabular}{ccccc}
\hline Year & k value & Actual value & Forecasted value & Residual error (F-A) \\
\hline $2007-08$ & 1 & $1,326,029$ & $1,326,029$ & 0 \\
$2008-09$ & 2 & $1,337,455$ & $1,337,553$ & 98 \\
$2009-10$ & 3 & $1,336,659$ & $1,340,641$ & 3,982 \\
$2010-11$ & 4 & $1,343,723$ & $1,343,735$ & 12 \\
$2011-12$ & 6 & $1,352,225$ & $1,346,837$ & $-5,388$ \\
$2012-13$ & 7 & $1,355,490$ & $1,349,946$ & $-5,544$ \\
$2013-14$ & 8 & $1,346,221$ & $1,353,061$ & 6,840 \\
$2014-15$ & 9 & $?$ & $1,356,185$ & $?$ \\
$2015-16$ & 10 & $?$ & $1,359,315$ & $?$ \\
$2016-17$ & 11 & $?$ & $1,362,452$ & $?$ \\
$2017-18$ & 12 & $?$ & $1,365,597$ & $?$ \\
\hline
\end{tabular}

Smaller MAPE value indicates better forecasting ability.

MAPE $=\frac{1}{n} \sum \frac{\mid \text { Actual-Forecast } \mid}{\text { Actual }} \times 100$

$B$ Forecasting number of step

Evaluation of MAPE forecasting ability is divided forecasting ability is evaluated as follows:

$-<10$ Excellent forecasting ability

-10 20 Good forecasting ability

- 20 50 Reasonable forecasting ability

$\bullet>50$ Poor forecasting

In order to ensure that the GM $(1,1)$ based on MATLAB has high accuracy for application in predicting the number in reality, this paper takes out the total number of students by discipline (as sample) in Taiwan from academic years 2007 to 2014 estimated by GM $(1,1)$ based on Matlab as $1,353,067$ which is very close to the original number $1,346,221$ and the error is so small in the Table 2 . Moreover, repeating above processes in the Table 2 showing the sample calculation by $\operatorname{GM}(1,1)$ based on MATLAB, it points out that the forecasting error ranging from only $0.0068 \%$ to $0.5060 \%$ in the sample predicted academic years. The result reveals that grey prediction is a good method for prediction. Apparently, the results of the ERRORS show that the GM $(1,1)$ has the best forecasting results in accuracy. The other two also have the very good accuracy when their sum of errors are $1.6994 \%$ and $1.6217 \%$ 
of Verhulst and DGM $(1,1)$ respectively. In Table 5,

the $\operatorname{GM}(1,1)$ forecasting errors are only $1.6208 \%$.

Table 5: The original and prediction values and errors (2007 2014)

\begin{tabular}{|c|c|c|c|c|c|c|c|}
\hline Year & Actual value & $\begin{array}{c}\text { Forecasted by } \\
\operatorname{GM}(1,1)\end{array}$ & $\begin{array}{c}\text { Forecasted by } \\
\text { Verhulst }\end{array}$ & $\begin{array}{c}\text { Forecasted } \\
\text { by } \operatorname{DGM}(1,1)\end{array}$ & $\begin{array}{l}\text { Error of } \\
\operatorname{GM}(1,1)\end{array}$ & $\begin{array}{c}\text { Error of } \\
\text { Verhulst }\end{array}$ & $\begin{array}{c}\text { Error of } \\
\operatorname{DGM}(1,1)\end{array}$ \\
\hline $2007-08$ & $1,326,029$ & $1,326,029$ & $1,326,029$ & $1,326,029$ & $0.0000 \%$ & $0.0000 \%$ & $0.0000 \%$ \\
\hline 2008-09 & $1,337,455$ & $1,337,546$ & $1,334,639$ & $1,337,553$ & $0.0068 \%$ & $0.2105 \%$ & $0.0073 \%$ \\
\hline $2010-11$ & $1,343,723$ & $1,343,733$ & $1,344,258$ & $1,343,735$ & $0.0008 \%$ & $0.0398 \%$ & $0.0009 \%$ \\
\hline 2011-12 & $1,352,225$ & $1,346,837$ & $1,346,823$ & $1,346,837$ & $0.4000 \%$ & $0.3995 \%$ & $0.3985 \%$ \\
\hline 2012-13 & $1,355,490$ & $1,349,949$ & $1,348,528$ & $1,349,946$ & $0.4105 \%$ & $0.5136 \%$ & $0.4090 \%$ \\
\hline \multirow[t]{2}{*}{ 2013-14 } & $1,346,221$ & $1,353,067$ & $1,349,660$ & $1,353,061$ & $0.5060 \%$ & $0.2555 \%$ & $0.5081 \%$ \\
\hline & & Sums of the ERRORS & & & $1.6208 \%$ & $1.6994 \%$ & $1.6217 \%$ \\
\hline
\end{tabular}

\section{Discussion and conclusion}

\subsection{The discussion of the results}

To the listed calculation results, it is shown that there would be the stable trend to the predicted numbers. Relied on the meaning of each digit, it's concerned that the Taiwanese people's affordability for the university and the society's educational structure are the main factors towards the impact of the development scale around the adult higher education in Taiwan, whereas the demographic structure of society, the employment structure of society and the level of economic development are comparatively the minor ones. After the further analysis of these indexes, we can find out some important information.

1. It is shown that the demand of Taiwanese society towards the well-educated or the high-leveleducated people is rising up based on the education structure of society, so that day by day more non-school-age faculty with not-high-levels of education will make decision on accepting tertiary education to get the improvement in their educational level and meet the social requirements.

2. The growing income of most of residents is one more reason for top priority of the investment in higher education.

3. The demographic structure, the working environment structure of society and the developing economy review the quick growth of Taiwanese society and economy from the macroscopic view. Such development takes no doubt a good part in the development of tertiary education in Taiwan.

To solve the problem of quantity and quality in the tertiary education should be based on the new ways of thinking and application of the new training technology.

In the recent 12 years, the total number of students has increased slightly - from 1,326,029 in 2007 to $1,346,221$ in 2014 , especially the pace has become a little faster in the next four years at 1,365,614 in 2018 (See Tables 5 and 6 and Fig. 2 to Fig. 5). Which make some education managers worried. The issue of managing quantity is in place a harsh and it is reflected more on the public opinion.

\subsection{The position of education for economic and social development}

Education plays important role increasingly: The rapid development of the science and technology is one of the causes to the increasing competition between countries and global economic organizations. A country wishing to keep up with development trends should have the well-qualified human resources. To build that capable and qualified workforce, education is both a challenge and also an opportunity, or just a mission for any country. This job is even more difficult to Taiwan because its population decline.

Education contributes to preserve national identity, to selectively absorb the cultural essence of humanity, integration in to global economy: Education is the most effective way to promote traditional values and national cultural identity, and the quintessence of human culture.

Table 5: Educational expenditure per student at university and college (Unit: NT\$)

\begin{tabular}{ccccc}
\hline $\begin{array}{c}\text { Kalues } \\
\text { School Years }\end{array}$ & $\begin{array}{c}\text { Original } \\
(1)\end{array}$ & $\begin{array}{c}\text { Prediction } \\
(2)\end{array}$ & $\begin{array}{c}\text { Error } \\
{[(2-} \\
1) / 1] \%\end{array}$ & AGO \\
\hline $2007-08$ & 171,965 & 171,965 & $0.0000 \%$ & 171,965 \\
$2008-09$ & 175,263 & 174,444 & $0.4671 \%$ & 347,228 \\
$2009-10$ & 182,649 & 180,184 & $1.3492 \%$ & 529,877 \\
$2010-11$ & 183,955 & 186,113 & $1.1730 \%$ & 713,832 \\
$2011-12$ & 188,506 & 192,237 & $1.9795 \%$ & 902,338 \\
$2012-13$ & 199,573 & 198,563 & $0.5062 \%$ & $1,101,911$ \\
$2013-14$ & 206,827 & 205,096 & $0.8367 \%$ & $1,308,738$ \\
$2014-15$ & $?$ & 211,845 & $?$ & $?$ \\
$2015-16$ & $?$ & 218,816 & $?$ & $?$ \\
$2016-17$ & $?$ & 226,016 & $?$ & $?$ \\
$2017-18$ & $?$ & 233,453 & $?$ & $?$ \\
\hline
\end{tabular}

It is not only a goal but also the driving force for economic development which can create a good life, happiness and social justice. Thanks to the education that each person has the intellectual capacity, knowledge and professional abilities. Moreover, that the large number of students has the chance to go aboard to study or stay in the good foreign institutes to achieve the international knowledge is the good trend for the stable development.

\subsection{Suggestions, conclusions and future works}

It is a great opportunity for students, students to access to advanced knowledge, learning methods and modern research, and contact with the cultures 
of countries around the world. However, the question is that not everyone gets the opportunity. The number of students studying aboard is accounted for only a very small percentage of the total number of pupils and students all over Taiwan. Besides, if viewed in economic relations, the foreign studying abroad is a form of purchased services in another country, and then it would lose an amount of foreign currency. That's not to mention numerous men have not returned after studying, but continued living and working abroad. This can lead to the brain drain for developing countries.

Meanwhile, foreign direct investment in education services can solve the above disadvantages, when foreign investors build scientific research institutions, schools and facilities for higher learning and research. Thus, researchers, lecturers, pupils, students can study and learn a country; it can lead to the result that foreign investment in local education can save costs and avoid the brain drain phenomenon.

Table 6: Percentages of learning trends in recent years

\begin{tabular}{cccc}
\hline Disciplines & $2007-08$ & $2013-14$ & $2017-18$ \\
\hline Education & $3.3170 \%$ & $2.8750 \%$ & $2.6159 \%$ \\
Humanities and Arts & $13.2626 \%$ & $15.3713 \%$ & $16.8940 \%$ \\
Social Sciences, Business & $26.1409 \%$ & $24.4680 \%$ & $23.3864 \%$ \\
and Law & $10.8328 \%$ & $9.8356 \%$ & $9.4335 \%$ \\
Science & & & \\
Engineering, & $25.2427 \%$ & $21.6011 \%$ & $19.3653 \%$ \\
Manufacturing and & & & \\
Construction & $2.0006 \%$ & $2.0792 \%$ & $2.1591 \%$ \\
Agriculture & $11.7945 \%$ & $11.4861 \%$ & $11.2282 \%$ \\
Health and Welfare & $7.3019 \%$ & $12.1655 \%$ & $17.0549 \%$ \\
Services & $0.1070 \%$ & $0.1183 \%$ & $0.0781 \%$ \\
Unspecified & & & \\
\hline
\end{tabular}

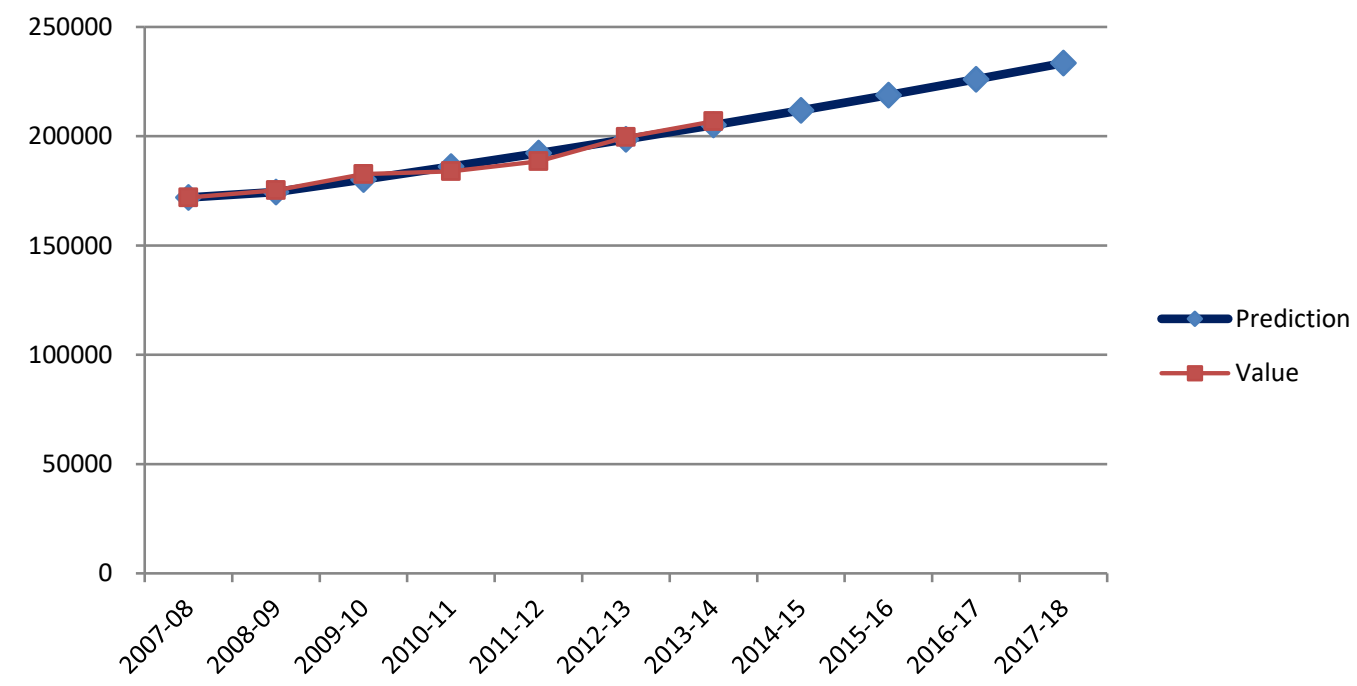

Fig. 2: Prediction value for educational expenditure per student at university and college

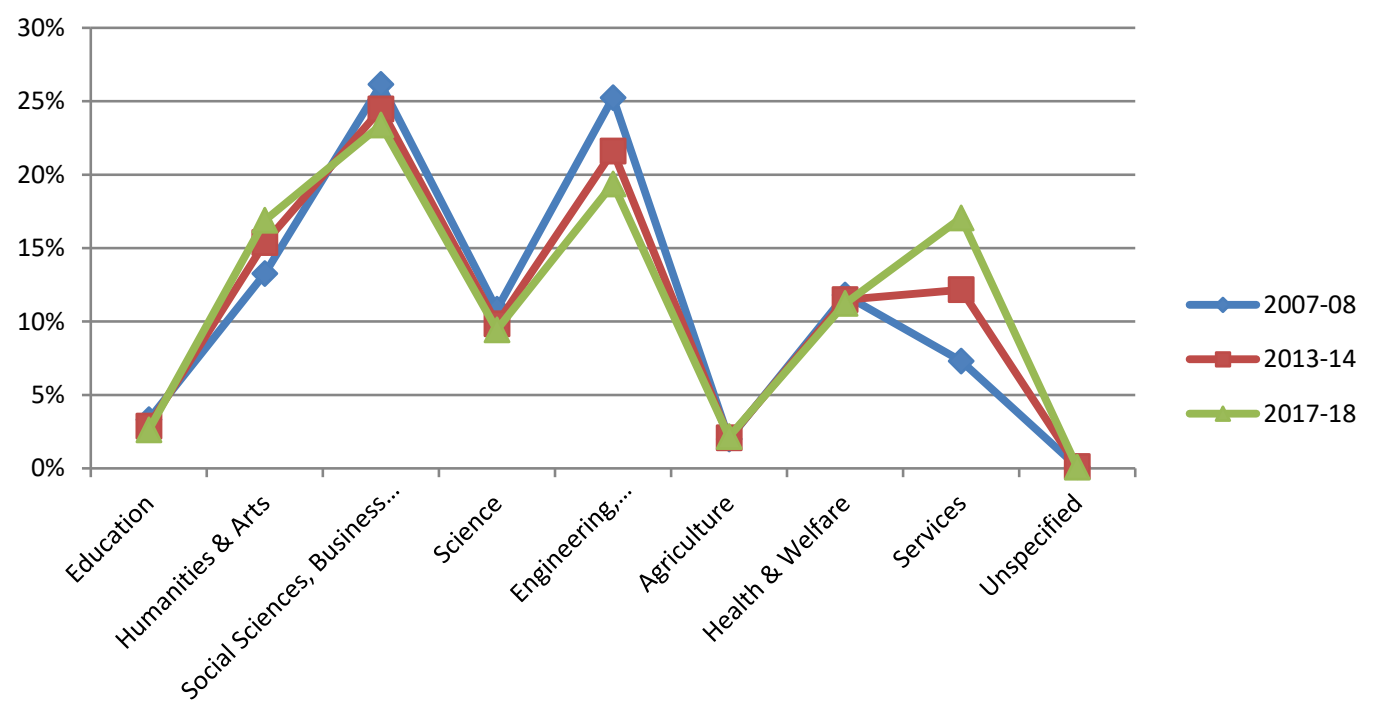

Fig. 3: Summary of learning trends in recent years

According to the research of this paper, we can arrive at a conclusion that the development scale of adult is becoming stable, the affordability of residents to adult higher education, the level of economic development and so forth.
However, because of the weak regularity of related data about adult higher education of the country, the results of this study probably contain some errors compared with the facts. Therefore, how to improve the reliability of application grey system 
theory in the field of research on adult higher education will become a focus of further research. Moreover, with the attained results from this research, we strongly suggest Ministry of Taiwanese Education and Training to use this method to apply for future calculates, for instance, high school or maybe the whole educational system so that, it is so important to have good strategies to make good development for Taiwanese education system.

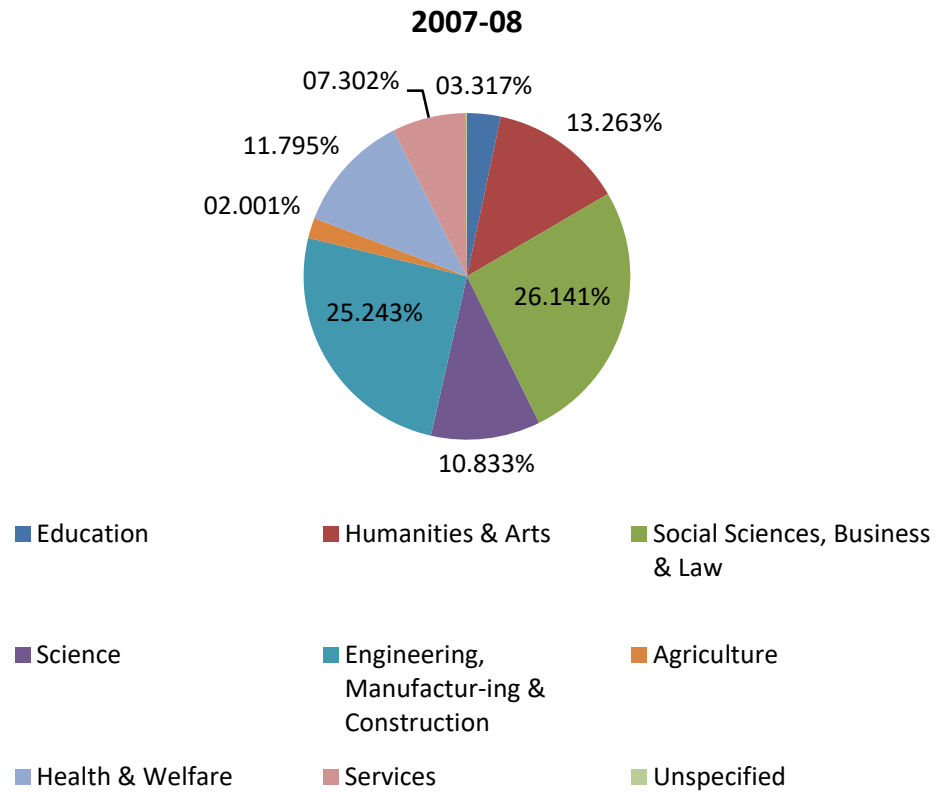

Fig. 4: Percentages of students by discipline in 2007-08

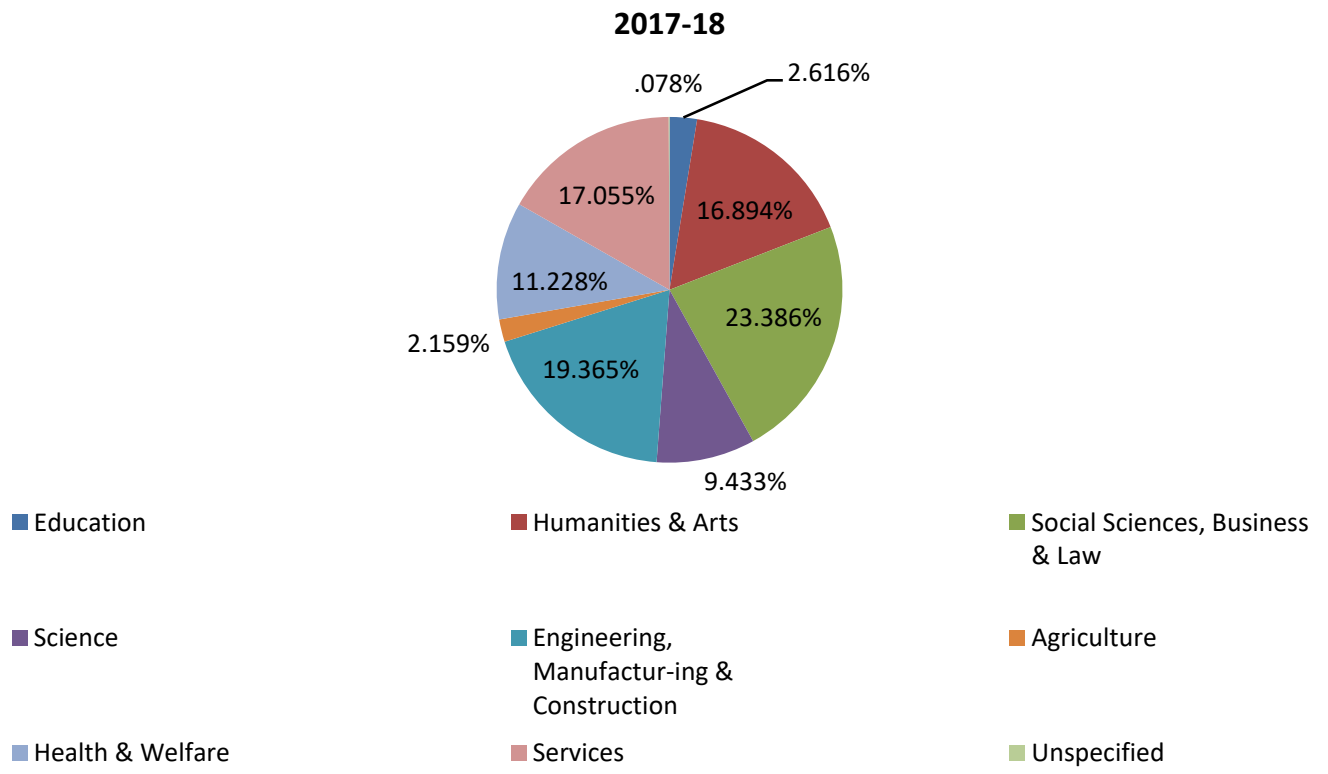

Fig. 5: Percentages of students by discipline in 2017-18 (as predicted results)

\section{References}

Bourguignon F, Ferreira FH, and Lustig N (2005). The microeconomics of income distribution dynamics in East Asia and Latin America. World Bank and Oxford University Press, Washington DC, USA.

Cheng CC (2003). Forecasting the benefit of a university based on the grey model. Journal of Nanjing Institute of Technology: Natural Science Edition, 1(1): 59-66.
Deng JL (1986). Grey prediction and grey decision. Press of Huazhong University of Science and Technology, Wuhan, China.

Deng JL (1989). Introduction to grey system theory. The Journal of Grey System, 1(1): 1-24.

Huang JT, Kao AP, and Hung WC (2006).The influence of college tuition and fees on fertility rate in Taiwan. Journal of Family and Economic Issues, 27(4): 626-642. 
Huang KY and Jane CJ (2009). A hybrid model for stock market forecasting and portfolio selection based on ARX, grey system and RS theories. Expert Systems with Applications, 36(3): 5387-5392.

Kayacan E, Ulutas B, and Kaynak 0 (2010). Grey system theorybased models in time series prediction. Expert Systems with Applications, 37(2): 1784-1789.

Lin TC (2004). The role of higher education in economic development: An empirical study of Taiwan case. Journal of Asian Economics, 15(2): 355-371.

Lin Y and Liu S (2004). A historical introduction to grey systems theory. In the IEEE International Conference on Systems, Man and Cybernetics, The Hague, Netherlands, 3: 2403-2408. https://doi.org/10.1109/ICSMC.2004.1400689

Liu S, Dang Y, Fang Z, and Xie NM (2004). Grey system theory and its application. Science Press, Beijing, China.

MOE (2013). Education in Taiwan. Ministry of Education Available online at: https://stats.moe.gov.tw/files/ebook/ Education_in_Taiwan/2013-2014_Education_in_Taiwan.pdf

Nguyen NT and Tran TT (2015). Mathematical development and evaluation of forecasting models for accuracy of inflation in developing countries: A case of Vietnam. Discrete Dynamics in Nature and Society. 2015: Article ID 858157, 14 pages. https://doi.org/10.1155/2015/858157

Nguyen NT and Tran TT (2016). Facilitating an advanced product layout to prioritize hot lots in $450 \mathrm{~mm}$ wafer foundry in the semiconductor industry. International Journal of Advanced and Applied Sciences, 3(6): 14-23.

Nguyen NT and Tran TT (2017a). A novel integration of DEA, GM $(1,1)$ and neural network in strategic alliance for the Indian electricity organizations. The Journal of Grey System, 29(2): 80-102.
Nguyen NT and Tran TT (2017b). Optimizing mathematical parameters of Grey system theory: an empirical forecasting case of Vietnamese tourism. Neural Computing and Applications: 1-15. Available online at: https:// link.springer.com/article/10.1007/s00521-017-3058-9

Nguyen NT, Tran TT, Wang CN, and Nguyen NT (2015). Optimization of strategic alliances by integrating DEA and grey model. Journal of Grey System, 27(1): 38-56.

Tang QY and Feng MG (2007). DPS data processing system: Experimental design, statistical analysis and data mining. Science Press, Beijing, China.

Wang CN, Nguyen NT, Tran TT, and Huong BB (2015). A Study of the strategic alliance for EMS industry: The application of a hybrid DEA and GM $(1,1)$ approach. 2015: Article ID 948793, 14 pages. https://doi.org/10.1155/2015/948793

Wen KL and Huang YF (2004). The development of grey Verhulst toolbox and the analysis of population saturation state in Taiwan-Fukien. In the IEEE International Conference on Systems, Man and Cybernetics, IEEE, The Hague, Netherlands, 6: 5007-5012. https://doi.org/10.1109/ICSMC.2004.1400986

Wu CC (2009). Higher education expansion and low-income students in Taiwan. International Journal of Educational Development, 29(4): 399-405.

Yao G, Cheng YP, and Cheng CP (2009).The quality of life in Taiwan. Social Indicators Research, 92(2): 377-404.

Zhang Y and Li M (2010). Grey system forecasting based on MATLAB and its example application. In the $2^{\text {nd }}$ IEEE International Conference on Information Management and Engineering, IEEE, Chengdu, China: 48-52. https://doi.org/10.1109/ICIME.2010.5477584 